\title{
Effects of various irrigation/aspiration protocols on cleaning of flattened root canals
}

\section{Diego Henrique da Silva \\ MENDONÇA \\ Vivian COLUCCI \\ Fuad Jacob Abi RACHED-JUNIOR \\ Carlos Eduardo Saraiva MIRANDA \\ Yara Teresinha Corrêa SILVA-SOUSA \\ Silvio Rocha Corrêa da SILVA}

Universidade de Ribeirão Preto - UNAERP, School of Dentistry, Department of Dentistry, Ribeirão Preto, SP, Brazil.

Declaration of Interests: The authors certify that they have no commercial or associative interest that represents a conflict of interest in connection with the manuscript.

Corresponding Author:

Vivian Colucci

E-mail:vi.colucci@gmail.com

DOI: 10.1590/1807-3107BOR-2015.vol29.0082

Submitted: Jan 07, 2015

Accepted for publication: Mar 10, 2015

Last revision: May 27, 2015

\begin{abstract}
This study aimed to evaluate, by means of scanning electron microscopy (SEM), the cleaning of flattened root canals, varying irrigation/aspiration protocols during biomechanical preparation. Thirdy human mandibular incisors were distributed into three groups ( $n=10)$ according to the aspiration/irrigation protocols: conventional, conventional + brush, and apical negative pressure irrigation. Irrigation procedure was performed with $5 \mathrm{~mL}$ of $1 \% \mathrm{NaOCl}$ at each change of instrument; final irrigation was conducted with 17\% EDTA for $5 \mathrm{~min}$. After biomechanical preparation, the roots were sectioned and prepared for SEM analysis. The images obtained were evaluated under $35 \times$ and 1,000× magnification by three calibrated examiners, following a double-blind design. All data were analyzed using Kruskal-Wallis and Dunn's post hoc tests $(\alpha=0.05)$. Canals wherein the conventional method and apical negative pressure irrigation were employed revealed less debris, statistically different from the conventional + brush group $(p<0.05)$. Regarding the presence of smears, apical negative pressure irrigation was more effective in cleaning, showing lowest scores $(\mathrm{p}<0.05)$, compared with the other tested protocols. Comparing each root canal third revealed that the apical portion was difficult to clean as all the tested protocols showed similar high scores $(p>0.05)$, both for the presence of debris and smear layer. In conclusion, although none of the studied irrigation/aspiration protocols have completely cleaned flattened root canals, apical negative pressure irrigation was more effective in smear layer removal, whereas the conventional + brush protocol was the least effective in removing the debris and smear layer.
\end{abstract}

Keywords: Endodontics; Smear Layer; Microscopy.

\section{Introduction}

The removal of vital and necrotic pulpal tissues, microorganisms, and bacterial products from the root canal system is important in endodontic therapy. ${ }^{1}$ However, around $35 \%$ of canal walls remain untouched by instruments during biomechanical preparation; ${ }^{2}$ thus, an efficient irrigation is necessary for a successful endodontic treatment. To dissolve organic materials ${ }^{3}$ and facilitate the removal of inorganic components present in the smear layer, ${ }^{4}$ the use of $\mathrm{NaOCl}$ combined with EDTA has been proposed. Because of the anatomical complexity of root canals, an effective contact of the irrigating solutions with the entire canal walls is 
difficult. Therefore, irrigation/aspiration techniques have been proposed for enhancing the effectiveness of irrigation solutions on the root canal system. ${ }^{5}$

The physicochemical properties inherent to each irrigating solution and its continuous renewal during biomechanical preparation maintain debris in suspension within the canal, preventing saturation and precipitation of particles ${ }^{6}$ and favoring their removal with the irrigation/aspiration process.

Various irrigation/aspiration methods, such as the conventional method that uses the Luer-lock syringe connected to different types and calibers of irrigation needles, ${ }^{7}$ ultrasound ${ }^{8}$ and sonic devices, ${ }^{9}$ brush-assisted irrigation, ${ }^{10,11}$ and hydrodynamic irrigation systems $\mathrm{s}^{12,13}$ have been proposed for improving the cleanliness of the root canal system. However, contradictory results have been found for these techniques.

The present study aimed to evaluate, by scanning electron microscopy (SEM) analysis, the removal of debris and smear layer from flattened root canals by comparing three irrigation/aspiration protocols: conventional, conventional + brush, and apical negative pressure irrigation. The following null hypotheses were tested: 1) The use of different irrigation/aspiration protocols has no influence on the cleanliness of the root canal and 2) Distinct regions of the root canal do not influence the results of various cleaning techniques.

\section{Methodology}

This study was approved by the Ethics Committee of the Universidade de Ribeirão Preto (CAAE: 13263313.3.0000.5498). Third sound one canal human mandibular incisors with completely formed roots, without calcifications, and without a strong curvature were sectioned at the enamel-cement junction using a diamond disc (KG Sorensen, São Paulo, Brazil) adapted to a low-speed handpiece (Dabi Atlante, Ribeirão Preto, Brazil) to obtain 15-mm long roots. Furthermore, to determine the real working length, the canal was explored to its full extension using a \#15 K-file (Dentsply-Maillefer, Ballaigues, Switzerland) until the tip coincided with the apical foramen, reducing $1 \mathrm{~mm}$ from the obtained measurement. The roots were adapted and stabilized in a condensation silicone base (Perfil Vigodent, Rio de Janeiro, Brazil) to retain the irrigating solution within the canal, avoiding its leakage through the apical foramen.

The instrumentation of the root canals was performed with a ProTaper Universal rotatory system (Dentsply-Maillefer) as follows: Sx, S1, and S2 in the cervical and middle third incisors and F1 and F2 in the real working length.

The roots were distributed into three groups $(\mathrm{n}=10)$ according to the employed irrigation/aspiration protocol: I, conventional; II, conventional + brush; and III, apical negative pressure irrigation.

In group I (control), the conventional irrigation was performed with $5 \mathrm{~mL}$ of $1 \% \mathrm{NaOCl}$ solution using a precision syringe pump attached to a 30 -gauge, flat, open-ended NaviTip needle (Ultradent Products, South Jordan, USA) inserted into the canal $1 \mathrm{~mm}$ from the real working length, without arresting the canal walls. This setting allowed the irrigating solution to flow during aspiration. After the last irrigation with $1 \% \mathrm{NaOCl}$, the canal was flooded with $5 \mathrm{~mL}$ of $17 \%$ EDTA for $5 \mathrm{~min}$ and aspirated using flexible capillary tips (Ultradent Products, South Jordan, USA).

In group II, the irrigation protocol was performed as described in group I; however, the irrigating solution was activated with a medium-sized rotatory Roeko CanalBrush (Coltène, Langenau, Germany) attached to a 600-rpm low-speed handpiece (Dabi Atlante) rotating clockwise. Cervical-apical movements were performed against the root canal walls for $30 \mathrm{~s}$ while the irrigating solution was being aspirated. After the instrumentation, the canal was flooded with $5 \mathrm{~mL}$ of 17\% EDTA for $5 \mathrm{~min}$ and aspirated using flexible capillary tips (Ultradent Products).

In group III, irrigation was performed using the EndoVac system (Discus Dental, Culver City, USA). At each change of instrument, $5 \mathrm{~mL}$ of $1 \% \mathrm{NaOCl}$ solution was inserted into the canal using a master delivery tip cannula. After $30 \mathrm{~s}$, the solution was aspirated with the macrocannula placed $2 \mathrm{~mm}$ from the real working length. After the last instrument, a final irrigation with $1 \% \mathrm{NaOCl}$ was performed for $30 \mathrm{~s}$. The microcannula was used in performing alternating corono-apical movements for the remaining $6 \mathrm{~s}$ at the real working length, followed by the same movements at $2 \mathrm{~mm}$ below the real working length for $30 \mathrm{~s}$. A 
cycle of macro- and microirrigation was performed with 17\% EDTA for 5 min.

In all groups, after irrigation with EDTA, neutralization was performed using $1 \mathrm{~mL}$ of $1 \%$ $\mathrm{NaOCl}$, followed by aspiration with capillary tips (Ultradent Products) and subsequent irrigation with $10 \mathrm{~mL}$ of distilled and deionized water. All root canals were aspirated with capillary tips (Ultradent Products) and dried with \#35 absorbent paper points.

The roots were then split into 2 halves, which were metalized with a Denton Desk II sputter coating system (Denton Vacuum, Nova Jersey, EUA) and examined under SEM (JOEL JSM model 5410; JEOL Ltd., Tokyo, Japan) equipped with a $15-\mathrm{kV}$ tungsten filament, operating at a vacuum of $10^{-4} \mathrm{~Pa}$.

After surface assessment of specimens by SEM, representative photomicrographs of the apical, middle, and cervical regions of the radicular canal were obtained under $35 \times$ and $1,000 \times$ magnification for evaluating the presence of debris and smear layer, respectively. The images were then qualitatively evaluated in a double-blind mode by three calibrated evaluators. The scores used in this study were adapted from those described by Parente et al. ${ }^{14}$ and are shown in Table 1.

Statistical analysis was performed using Kruskal-Wallis and Dunn's post hoc test $(\alpha=0.05)$ using the SPSS 17.0 software (IBM, New York, USA). Kappa coefficient was used for testing inter- and intra-examiner reproducibility using the criteria described by Landis and Koch. ${ }^{15}$

\section{Results}

The inter-examiner Kappa coefficient was 0.795 (0.625-0.965) with $79 \%$ reproducibility. The intra-examiner Kappa coefficient was 0.863 (0.751-0.924) with $86 \%$ reproducibility.

Table 2 shows the percentage of scores for the debris and smear layer removal, according to each irrigation/aspiration protocol.

Statistically significant differences in debris removal in the entire root canal were observed among the groups ( $p<0.05)$, with conventional irrigation and apical negative pressure irrigation showing lesser debris, being statistically similar between them $(p>0.05)$ and different from conventional + brush group ( $\mathrm{p}<0.05)$, in which more debris was found.

Comparison of the cleanliness on the root canal thirds showed statistical differences between the cervical and middle third ( $p<0.05)$, wherein the conventional + brush group showed a lower degree of cleanliness and was significantly different from that observed in the conventional and apical negative pressure groups $(\mathrm{p}<0.05)$. No statistical difference

Table 1. Scores employed to classify debris and smear layer removal.

\begin{tabular}{lcc}
\hline Score & Debris & Smear \\
\hline 1 & Clean walls, without debris & Absence of smear layer and open dentinal tubules \\
2 & Walls with little scattered debris & Little smear layer, covering the surface and open dentinal tubules \\
3 & Walls with debris clusters covering $<50 \%$ of the surface & Smear layer covering up to $50 \%$ of the surface and some open dentinal tubules \\
4 & Walls with debris clusters covering $>50 \%$ of the surface & Smear layer covering $>50 \%$ of the surface and several open dentinal tubules \\
5 & Walls completely covered by debris & Walls completely covered by smear and absence of open dentinal tubules \\
\hline
\end{tabular}

Table 2. Scores (\%) for the debris and smear layer removal using each irrigation/aspiration protocol.

\begin{tabular}{|c|c|c|c|c|c|c|}
\hline \multirow{2}{*}{ Score } & \multicolumn{2}{|c|}{ Conventional } & \multicolumn{2}{|c|}{ Conventional + brush } & \multicolumn{2}{|c|}{ Apical negative pressure } \\
\hline & Debris $^{a}$ & Smear" & Debris $^{b}$ & Smear - & Debris $^{a}$ & Smear \\
\hline 1 & --- & --- & --- & --- & 2.1 & --- \\
\hline 2 & 11.8 & 9.8 & 2.1 & 8.2 & 13.4 & 36.8 \\
\hline 3 & 29.2 & 37.2 & 15.6 & 20.4 & 27.9 & 30.6 \\
\hline 4 & 25.7 & 15.8 & 47.1 & 34.2 & 29.2 & 12.2 \\
\hline 5 & 33.3 & 37.2 & 35.2 & 37.2 & 27.4 & 20.4 \\
\hline
\end{tabular}

*Different lefters and symbols indicate statistically significant differences $(p<0.05)$ for the debris and smear layer, respectively. 
among the tested protocols was observed in the apical third $(p>0.05)$. The median values for each irrigation/aspiration protocol considering each root canal third are shown in Table 3.

Statistically significant differences in smear removal in the entire root canal was observed among groups ( $\mathrm{p}<0.05)$, with the apical negative pressure group showing the lowest scores relative to that observed in the conventional and conventional + brush groups $(\mathrm{p}<0.05)$, which presented similar degrees of smear removal $(p>0.05)$.

For the cervical and middle thirds, the conventional and apical negative pressure groups revealed less debris $(p>0.05)$ and were different from that observed in the conventional + brush group $(p<0.05)$. In the apical third, no statistical difference was observed among tested groups $(\mathrm{p}>0.05)$.

Figures 1, 2, and 3 show representative SEM photomicrographs of the root canal subjected to conventional, conventional + brush, and apical negative pressure irrigation/aspiration protocols, respectively.

\section{Discussion}

The present study showed that the three tested irrigation/aspiration protocols were unable to completely remove the debris and smear layer from flattened root canals. Debris was detected in areas untouched by instruments, particularly in flattened zones, despite the use of $\mathrm{NaOCl}$ combined with EDTA in all the tested protocols.

The conventional irrigation/aspiration + brush protocol showed the greatest amount of debris on the root canal walls. However, presently, this finding remains contradictory. Previous studies ${ }^{10,16,17,18}$ have also failed to show an improved cleanliness using the conventional irrigation + brush protocol, whereas other studies have proved its effectiveness in cleaning. ${ }^{11,19}$ Certain factors have to be considered when comparing these studies. The type of brushes used in these studies was not standardized, and in some studies, it was employed to shake the $\mathrm{NaOCl}$ solution $^{10}$ and stir the EDTA solution; ${ }^{11,16}$ however, in another study, the brush was used for agitating both solutions. ${ }^{5}$ Furthermore, in the aforementioned studies, ${ }^{5,10,11,16}$ the brush was employed during the final irrigation at the end of the chemomechanical preparation and not at each change of instrument, as performed in the present study. Another factor that must be considered is the varying size of the brush. When the brush diameter was compatible with that obtained from canal instrumentation, a lower degree of cleanliness was observed, ${ }^{10}$ similar to that described in the present study.

Another aspect that needs to be addressed is that the studies used different types of teeth for analysis, which possess distinct root canal morphology. The use of brushes in the conventional irrigation/aspiration protocol was as effective as ultrasound irrigation in removing debris and smear layer in the roots of molar. ${ }^{19}$ However, in the present study, anterior teeth were employed, which have flattened areas ${ }^{6,20}$ that may interfere with the bristles of the brush, favoring debris deposition on the wall. Moreover, Garip et al. ${ }^{16}$ and Salman et al. ${ }^{17}$ have also failed to show the advantages in cleaning the root canal of anterior teeth using the conventional irrigation/aspiration + brush protocol compared with the conventional method. According to Ribeiro et al. ${ }^{13}$ the bristles promote mechanical abrasion of the tissue, hinder the flow of the solution, and consequently, decrease the removal of debris due to the contact with dentinal walls.

Comparison on the root canal thirds, revealed difficulty in cleaning the apical region, as indicated

Table 3. Median values for the removal of debris and smear layer using various irrigation/aspiration protocols, considering each root canal third.

\begin{tabular}{|c|c|c|c|c|c|c|}
\hline & \multicolumn{2}{|c|}{ Conventional } & \multicolumn{2}{|c|}{ Conventional + brush } & \multicolumn{2}{|c|}{ Apical negative pressure } \\
\hline & Debris & Smear & Debris & Smear & Debris & Smear \\
\hline Cervical & $3^{a}$ & $3^{a}$ & $4^{b}$ & $4^{b}$ & $3^{a}$ & $3^{a}$ \\
\hline Middle & $3 \bullet$ & $3^{\bullet}$ & $4 \cdot$ & $4 \cdot$ & $3 \bullet$ & $3 \bullet$ \\
\hline Apical & $4^{\mathrm{A}}$ & $4^{\mathrm{A}}$ & $4^{\mathrm{A}}$ & $4^{\mathrm{A}}$ & $4^{\mathrm{A}}$ & $4^{\mathrm{A}}$ \\
\hline
\end{tabular}

*Different letters and symbols indicate statistically significant differences $(p<0.05)$ for the debris and smear layer, respectively 

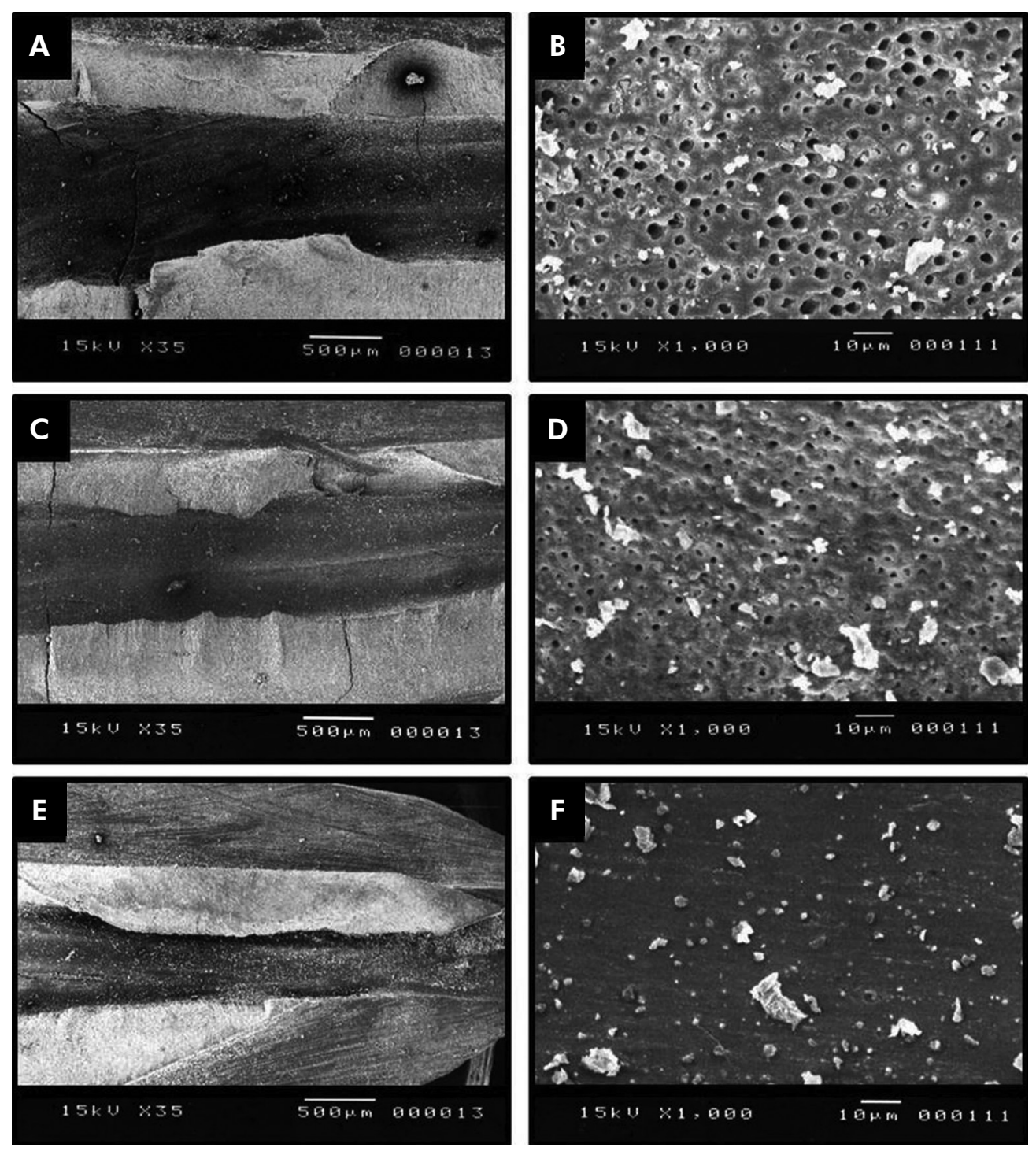

Figure 1. Representative SEM photomicrographs of the conventional syringe needle protocol. A) Cervical third with the debris covering the entire surface $(35 \times)$; B) Cervical third with the smear layer covering $<50 \%$ of the surface $(1,000 \times)$; C) Middle third with the debris covering $>50 \%$ of the surface $(35 \times)$; D) Middle third with the smear layer and some visible tubules $(1,000 \times)$; E) Apical third with debris agglomerations on the canal walls $(35 \times)$; F) Apical third with the smear layer and dentinal tubules totally obliterated $(1,000 \times)$.

by the statistically similar higher scores using all tested protocols for both the debris and smear layer removal. Available irrigation methods can be effective in cleaning the cervical and middle thirds, although these are less effective on the apical region, ${ }^{17,21,22}$ probably because of the small diameter of the canal, which restricts the flow of the irrigating solution, reducing the hydrodynamic flow.

In terms of the smear layer removal, best results were observed with the apical negative pressure irrigation protocol compared with the conventional and conventional + brush protocol, which showed similar results. The smear layer covering up to $50 \%$ of the surface and several open dentinal tubules were predominant in specimens from the apical negative pressure group. The EndoVac system (Discus Dental) aspirates the irrigating solution faster than it is inserted into the root canal, creating an air induction system and two-phase flow fluid dynamics. ${ }^{23}$ Furthermore, the combined use of micro- and 

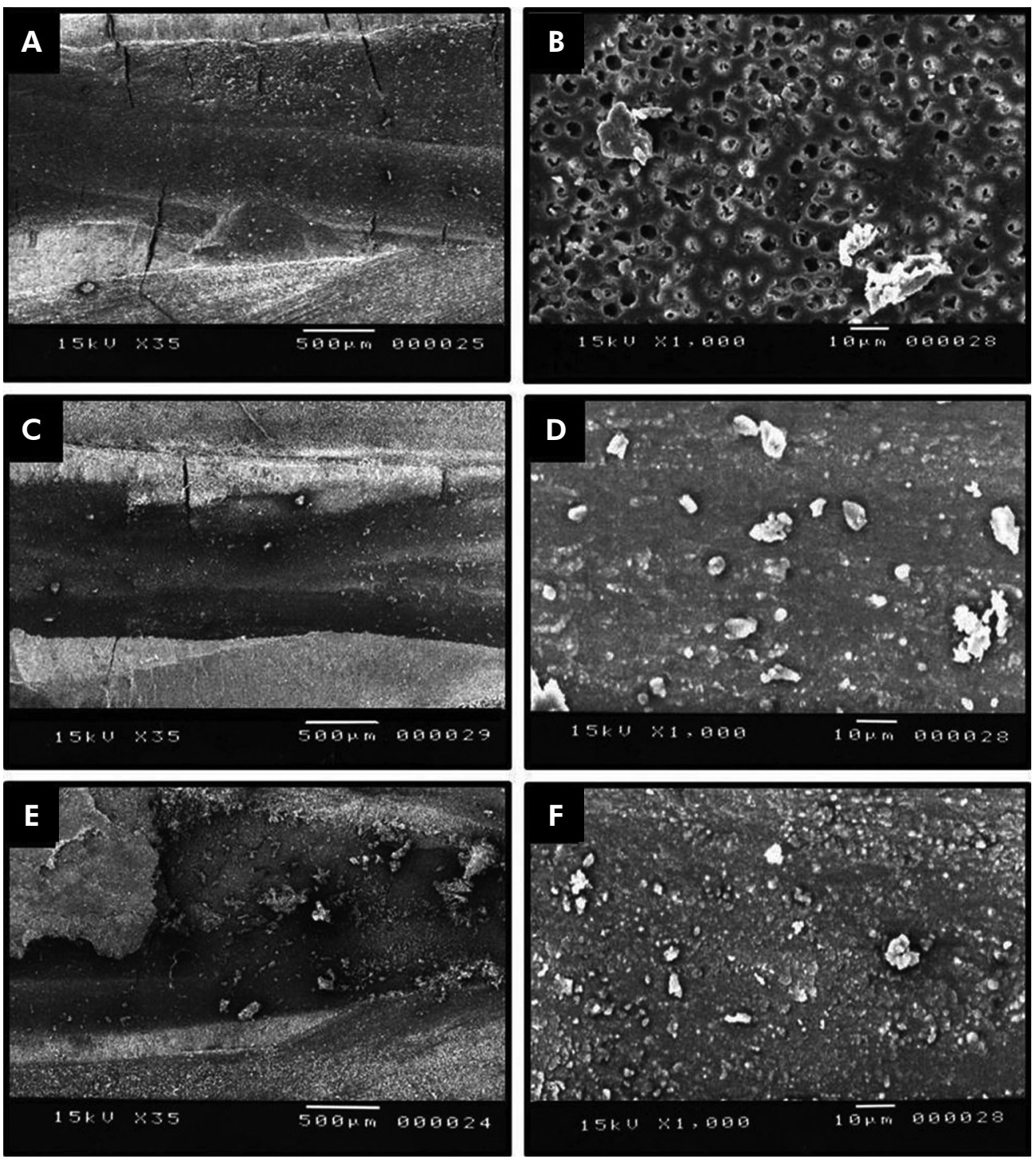

Figure 2. Representative SEM photomicrographs of the conventional irrigation/aspiration + brush protocol. A) Cervical third with the wall covered by debris $(35 \times)$; B) Cervical third with the smear layer and dentinal tubules partially obliterated $(1,000 \times)$; C) Middle third with the debris covering $>50 \%$ of the surface $(35 \times)$; D) Middle third with the smear layer and dentinal tubules totally obliterated $(1,000 \times)$; E) Apical third with the debris clusters within the canal $(35 \times)$; F) Apical third with the smear layer and dentinal tubules completely covered $(1,000 \times)$.

macrocannulas generates a pressure difference and produces a vacuum inside the canal, ${ }^{12,24,25}$ and an incessant flow of the irrigant is supplied by the negative pressure to the working length. ${ }^{26}$ Apical negative pressure irrigation promotes a rapid movement and constant replacement of the irrigating solution inside the canal ${ }^{13}$ because during the same time period, the volume of irrigant delivered into the canal is markedly higher than that delivered into the canal by conventional syringe needle irrigation, ${ }^{12,22,27}$ which may have improved the removal of the smear layer.

Smear layer removal by apical negative pressure irrigation may have been favored by the contact time of the chelating agent with the canal walls. In the present study, EDTA was employed for $5 \mathrm{~min}$ because 3 min of contact is necessary for modifying the dentin microhardness. ${ }^{28}$ Ribeiro et al. ${ }^{13}$ used EDTA solution for $1 \mathrm{~min}$, which failed to improve smear layer removal using the apical negative pressure protocol. 

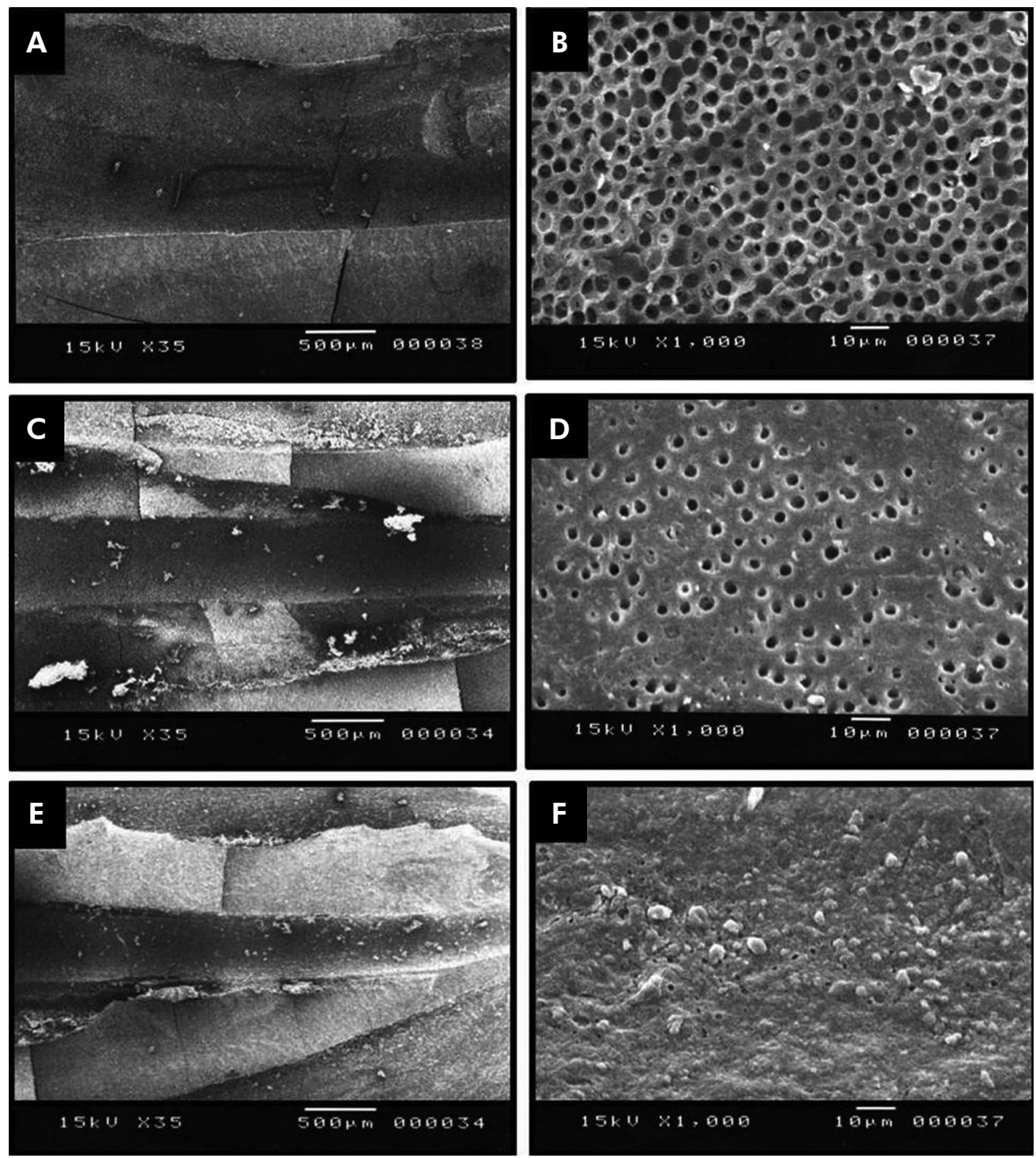

Figure 3. Representative SEM photomicrographs of the apical negative pressure irrigation protocol. A) Cervical third with debris $(35 \times)$; B) Cervical third with open dentinal tubules $(1,000 \times)$; C) Middle third with the debris scattered on the surface $(35 \times)$; D) Middle third with visible dentinal tubules $(1,000 \times)$; E) Apical third with $>50 \%$ of the surface covered with debris $(35 \times)$; F) Apical third with a few visible dentinal tubules and smear layer partially covering the surface $(1,000 \times)$.

\section{Conclusion}

In conclusion, none of the tested irrigation/aspiration protocols was capable of completely removing the debris and smear layer from flattened root canals. However, evaluation of the entire canal indicated that apical negative pressure irrigation generated best results for smear layer removal. Further, the conventional irrigation + brush protocol demonstrated the worst results in both the debris and smear layer removal, as shown by the cleanliness of the entire root and in the cervical and middle thirds. In the apical region, no difference in the effectiveness of removing the debris or smear layer was observed among the irrigation/aspiration protocols. 


\section{References}

1. Siqueira Júnior JF, Rôças IN, Santos SLRD, Lima KC, Magalhães FAC, Uzeda M. Efficacy of instrumentation techniques and irrigation regimens in reducing the bacterial population within root canals. J Endod. 2002 Mar;28(3):181-4.

2. Peters OA, Schonenberger K, Laib A. Effects of four Ni-Ti preparation techniques on root canal geometry assessed by micro computed tomography. Int Endod J. 2001 Apr;34(3):221-30.

3. Spanó JCE, Barbin EL, Santos TC, Guimarães LF, Pécora JD. Solvent action of sodium hypochlorite on bovine pulp and physico-chemical properties of resulting liquid. Braz Dent J. 2001;12(3):154-7.

4. Mello I, Kammerer BA, Yoshimoto D, Macedo MC, Antoniazzi JH. Influence of final rinse technique on ability of ethylenediaminetetraacetic acid of removing smear layer. J Endod. 2010 Mar;36(3):512-4. doi: 10.1016/j.joen.2009.11.004.

5. Topçuoglu HS, Tuncay O, Demirbuga S, Dinçer AN, Arslan $\mathrm{H}$. The effect of different final irrigant activation techniques on the bond strength of an epoxy resin-based endodontic sealer: a preliminary study. J Endod. 2014 Jun;40(6):862-6. doi: 10.1016/j.joen.2013.10.012.

6. Nadalin MR, Perez DE, Vansan LP, Paschoalato C, Sousa-Neto MD, Saquy PC. Effectiveness of different final irrigation protocols in removing debris in flattened root canals. Braz Dent J. 2009;20(3):211-4.

7. Jiang LM, Lak B, Eijsvogels LM, Wesselink P, Van der Sluis LW. Comparison of the cleaning efficacy of different final irrigation techniques. J Endod. 2012 Jun;38(6):838-4. doi: 10.1016/j.joen.2012.03.002.

8. Curtis TO, Sedgley CM. Comparison ultrasonic irrigation device and conventional needle irrigation in the removal of root canal debris. J Endod. 2012 Sep;38(9):1261-4. doi: 10.1016/j.joen.2012.05.012.

9. Kanter V, Weldon E, Nair U, Varella C, Kanter K, Anusavice $\mathrm{K}$, et al. A quantitative and qualitative analysis of ultrasonic versus sonic endodontic systems on canal cleanliness and obturation. OralSurg Oral Med Oral Pathol Oral Radiol Endod. 2011 Dec;112(6):809-13. doi: 10.1016/j.tripleo.2011.06.002.

10. Protogerou E, Arvaniti I, Vlachos I, Khabbaz MG. Effectiveness of a canal brush on removing smear layer: a scanning electron microscopy study. Braz Dent J 2013 Nov-Dec;24(6):580-4. doi: 10.1590/0103-6440201302272.

11. Kamel WH, Kataia EM. Comparison of the efficacy of smear clear with ad without canal brush in smear layer and debris removal from instrumented root canal using WaveOne versus Protaper: a scanning electron microscopy study. J Endod. 2014 Mar;40(3):446-50. doi: 10.1016/j.joen.2013.09.028.

12. Nielsen BA, Baumgartner JC. Comparison of the EndoVac system to needle irrigation of root canals. J Endod. 2007 May;33(5):611-5.

13. Ribeiro EM, Silva-Sousa YT, Souza-Gabriel EA, Sousa-Neto MD, Lorencetti KT, Silva SRC. Debris and smear removal in flattened root canals after use of different irrigant agitation protocols. Microsc Res Tech. 2012 Jun;75(6):781-90. doi: 10.1002/jemt.21125.

14. Parente JM, Loushine RJ, Susin L, Gu L, Looney SW, Weller $\mathrm{RN}$, et al. Root canal debridement using manual dynamic agitation or the EndoVac for final irrigation in a closed system and an open system. Int Endod J. 2010 Nov;43(11):1001-12. doi: 10.1111/j.1365-2591.2010.01755.x.

15. Landis JR, Koch GG. The measurement of observer agreement for categorical data. Biometrics. 1977 Mar;33(1):159-74.

16. Garip Y, Sazak H, Gunday M, Hatipoglu S. Evaluation of smear layer removal after use of a canal brush: an SEM study. Oral Surg Oral Med Oral Pathol Oral Radiol Endod. 2010 Aug;110(2):e62-6. doi: 10.1016/j.tripleo.2010.02.037.

17. Salman MI, Baumann MA, Hellmich M, Roggendorf MJ, Termaat S. SEM evaluation of root canal debridement with Sonicare CanalBrush irrigation. Int Endod J. 2010 May;43(5):363-9. doi: 10.1111/j.1365-2591.2009.01675.x.

18. Rödig T, Döllmann S, Konietschke F, Drebenstedt S, Hülsmann M. Effectiveness of different irrigant agitation techniques on debris and smear layer removal in curved root canals: a scanning electron microscopy study. J Endod. 2010 Dec;36(12):1983-7. doi: 10.1016/j.joen.2010.08.056.

19. Al-ali M, Sathorn C, Parashos P. Root canal debridement efficacy of different final irrigation protocols. Int Endod J. 2012 Oct;45(10):898-906. doi: 10.1111/j.1365-2591.2012.02046.x.

20. Fornari VJ, Silva-Sousa YT, Vanni JR, Pécora JD, Versiani MA, Sousa-Neto MD. Histological evaluation of the effectiveness of incresead apical enlargement for cleaning the apical third of curved canals. Int Endod J. 2010 Nov;43(11):988-94. doi: 10.1111/j.1365-2591.2010.01724.x.

21. Foschi F, Nucci C, Montebugnoli L, Marchionni S, Breschi L, Malagnino VA, et al. SEM evaluation of canal wall dentine following use of Mtwo and Protaper NiTi rotary instruments. Int Endod J. 2004 Dec;37(12):832-9.

22. Gregorio C, Arias A, Navarrete N, Del Rio V, Oltra E, Cohenca N. Effect of apical size and taper on volume of irrigant delivered at working lenght with apical negative pressure at different root curvatures. J Endod. 2013 Jan;39(1):119-24. doi: 10.1016/j.joen.2012.10.008.

23. Goode N, Khan S, Eid AA, Niu L, Gosier J, Susin LF, et al. Wall shear stress effects of different endodontic irrigation techniques and systems. J Dent. 2013 Jul;41:636-41.

24. Shin SJ, Kim HK, Jung IY, Lee CY, Kim E. Comparison of the cleaning efficacy of a new apical negative pressure irrigating system with conventional irrigation needles in the root canal. Oral Surg Oral Med Oral Pathol Oral Radiol Endod. 2010 Mar;109(3):479-84. doi: 10.1016/j.tripleo.2009.10.050.

25. Susin L, Liu Y, Yoon JC, Parente JM, Loushine RJ, Ricucci $\mathrm{D}$, et al. Canal and isthmus debridement efficacies of two irrigant agitation techniques in a closed system. Int Endod J. 2010 Dec;43(12):1077-90. doi: 10.1111/j.1365-2591.2010.01778.x. 
26. Gu LS, Kim JR, Ling J, Choi KK, Pashley DH, Tay FR. Review of contemporary irrigant agitation techniques and devices. J Endod. 2009 Jun;35(6):791-804. doi: 10.1016/j.joen.2009.03.010.

27. Abarajithan, $M$, Dhan D, Velmurugan $N$, Valerian-Albuquerque D, Ballal S, Senthilkumar $\mathrm{H}$. Comparison of endovac irrigation system with conventional irrigation for removal of intracanal smear layer: an in vitro study. Oral Surg Oral Med Oral Pathol Oral Radiol Endod. 2011 Sep;112(3):407-11.

28. Cruz-Filho AM, Sousa-Neto MD, Saquy PC, Pecora JD. Evaluation of the effect of EDTAC, CDTA, and EGTA on radicular dentin microhardness. J Endod. 2001 Mar;27(3):183-4. 